\title{
DIREITO E TECNOLOGIA: NOVOS RUMOS DO DIREITO DAS SUCESSÕES FRENTE À SOCIEDADE DIGITAL
}

\author{
Eliane Aparecida Ribeiro* \\ Muriana Carrilho Bernardinel**
}

\section{RESUMO}

O surgimento da internet fez com que a sociedade evoluísse em todos os aspectos, ocasionando grandes desafios para o Direito. Neste cenário de revolução tecnológica é crescente a utilização de plataformas digitais para criação de contas, aquisição de produtos e serviços, criação de perfis em redes sociais, que juntos poderão vir a compor o acervo de bens digitais de um usuário. Busca-se com a pesquisa demostrar a relevância do tema, relacionando o direito à privacidade do de cujus e o direito dos herdeiros à herança digital, pois a temática encontra-se em uma lacuna legislativa a qual desafia a legislação para um novo modelo de sucessão, para que os bens digitais passem a ser regulamentados pelo Direito Sucessório. No presente trabalho utilizou-se da metodologia bibliográfica e exploratória, com pesquisa e revisão de bibliografia.

Palavras-chave: Redes socias; Bens Digitais; Privacidade; Sucessão.

\section{LAW AND TECHNOLOGY: NEW DIRECTIONS IN THE RIGHT OF- SUCCESSION BEFORE THE DIGITAL SOCIETY}

\section{ABSTRACT}

The emergence of the internet made society evolve in all aspects, bringing great challenges to the Law. In this scenario of technological revolution, the use of digital platforms for creating accounts, purchasing products and services, creating profiles on social networks, which together may come to compose a user's collection of digital goods, is increasing. The research seeks to demonstrate the relevance of the theme, relating the right to privacy of the deceased and the right of heirs to digital inheritance, as the theme is in a legislative gap, which challenges the legislation for a new succession model, so that digital goods can be regulated by Succession Law. In the present work,

* Bacharel em Direito pela Faculdade Santa Maria da Glória - SMG. Pós graduanda em Ciências Penais pela Universidade Estadual de Maringá - UEM. E-mail: elianeribeiro246@gmail.com

** Doutoranda em Função Social do Direito pela FADISP - Faculdade Autônoma de São Paulo. Mestre em Ciências Jurídicas com ênfase em Direitos da Personalidade pela UNICESUMAR - Centro Universitário de Maringá. Especialista em Direito do Trabalho e Previdenciário pelo IDCC - Instituto de Direito Constitucional e Cidadania em parceira com a UENP - Universidade Estadual do Norte do Paraná. Bacharel em Direito pela UEM - Universidade Estadual de Maringá. Docente do curso de Graduação em Direito na Faculdade Santa Maria da Glória. Docente da Pós-Graduação em MBA, Gestão de Pessoas e Marketing da Faculdade Santa Maria da Glória. Parecerista da Revista Científica do Curso de Direito da Universidade Metodista de São Paulo. Palestrante e ministrante de cursos. Advogada. E-mail: muriana_bernardineli@hotmail.com 
the bibliographic and exploratory methodology was used, with research and bibliography review.

Keywords: Social networks; Digital Goods; Privacy; Succession.

\section{INTRODUÇÃO}

Com a crescente evolução da tecnologia a vida em sociedade vem sendo modificada, os dados e informações pessoais estão cada vez mais disponíveis no ambiente virtual. Neste cenário, os indivíduos adquirem bens digitais como, músicas, filmes, livros, contas de e-mails e redes sociais. Muitos desses bens adquiridos possuem valor econômico, e quando o titular vem a falecer, podem servir aos herdeiros, se constituindo em herança.

Neste viés, busca-se trazer à baila os desafios jurídicos que surgem diante do progresso do mundo digital, bem como as novas espécies de relações jurídicas trazidas por este que alteram a forma de interpretar o direito de herança. Deste modo, este trabalho vem tratar sobre os novos rumos do Direito das Sucessões frente à sociedade digital.

Inicialmente a pesquisa irá abordar sobre o direito à privacidade como uma espécie do gênero direitos da personalidade. Adiante, discute-se sobre a proteção dos dados sensíveis que são os dados privativos e personalíssimos, aqueles que falam sobre a personalidade de modo geral, que dizem a própria pessoa e que estão expostos, seja de modo físico ou digital.

Posteriormente, é discutido sobre o direito à privacidade no rol dos direitos humanos fundamentais, já que a privacidade deve abarcar a proteção desse direito que se impõe como a única forma capaz de resguardar o livre desenvolvimento e a autodeterminação inerente à pessoa. Aqui a seção abordará sobre o direito à herança, partindo-se de sua conceituação e sua importância dentro do ordenamento jurídico brasileiro abordando o instituto da sucessão digital, apresentando sua origem e conceito.

Em seguida, trata-se do instituto da sucessão dos bens armazenados virtualmente, em que se constata que, por falta de legislação específica, a transferência e acesso dos bens virtuais acabam sendo ditadas pelos próprios provedores, como é o caso, por exemplo, do Facebook, Twitter, Instagram e Google os quais propõem as suas próprias soluções.

Nos tópicos seguintes aborda-se a colisão entre os direitos fundamentais da privacidade e da herança, indagando a respeito do Facebook ser um bem digital, se este deve abarcar o direito à herança ou o direito à privacidade, pois em muitos casos os herdeiros estão pleiteando o acesso aos dados privados dessa rede social.

Por fim, demonstra-se que é necessária a regulamentação da herança digital no ordenamento jurídico brasileiro, bem como a adaptação do Direito Sucessório quanto à regulamentação de transferência e acesso aos dados privados de bens virtuais, pois sem regulamentação específica engendram verdadeiras avalanches de impasses que aportam no mundo jurídico, causando insegurança jurídica e inúmeras controvérsias acerca do tema. 


\section{DIREITO À PRIVACIDADE COMO ESPÉCIE DO GÊNERO DIREI- TOS DA PERSONALIDADE}

Quando se fala em personalidade há diversas acepções sobre o tema como a pessoalidade, a qualidade ou o modo de existir como pessoa, é a condição ou a maneira de ser da pessoa, a forma como a pessoa se organiza e imprime a multiplicidade de relações que a constituem.

Segundo o entendimento de Anderson Schreiber (2014), a personalidade nada mais é do que a capacidade que tem toda pessoa de ser titular de direitos e obrigações, sendo um conjunto de características e atributos da pessoa humana.

Essa personalidade que está ligada aos atributos e características do ser humano é tutelada pelo Estado por meio dos chamados direitos da personalidade, sendo este essencial ao desenvolvimento da pessoa humana. Dentro do rol dos direitos da personalidade está o direito à privacidade como uma espécie do gênero, que engloba o direito à intimidade, à honra e à imagem. $\mathrm{O}$ direito à privacidade está relacionado à proteção da vida particular do indivíduo, o que abarca proteção a toda manifestação de cunho íntimo e não público (FARIAS; ROSENVALD, 2017).

Desde a concepção da humanidade o homem está preocupado em ter a sua intimidade e vida privada protegidas. $\mathrm{O}$ direito à privacidade é uma preocupação que faz parte da história, a bíblia demostra em seus ensinamentos que os primeiros seres humanos ficaram envergonhados quando se deparam nus diante de Deus, após comerem o fruto da árvore proibida. ${ }^{1}$

A partir de então, com o desenvolvimento da sociedade civil houve o reconhecimento por uma individualidade que quase sempre era focalizada no direito de estar só. No entanto, o direito à privacidade não se limita mais no "estar só", mas abrange também a proteção de seus dados pessoais, sendo suas características físicas, código genético, estado de saúde, crença religiosa e qualquer outra informação pertencente a pessoa (SCHREIBER, 2014).

O direito à privacidade é regulamentado pela Constituição Federal de 1988, sendo a dignidade da pessoa humana uma das bases do sistema. Os aspectos relacionados à intimidade, honra e imagem do indivíduo são atributos importantes para seu desenvolvimento e proteção de sua integridade, os quais são reconhecidamente tutelados pela ordem jurídica como um conjunto indeterminado de valores não redutíveis pecuniariamente.

Os direitos da personalidade são considerados primordiais à condição humana, são direitos sem os quais todos os outros direitos perderiam qualquer interesse para o indivíduo, ao ponto de se chegar a dizer que, se não existissem, a pessoa não seria mais pessoa (PERLINGIERI, 2007).

Alguns doutrinadores defendem que a personalidade não se constitui propriamente em um direito, mas em um atributo inerente à pessoa humana tomada em si mesma e em suas projeções na sociedade. A personalidade é qualidade, é o ser capaz de direitos, o ser possível de estar nas relações jurídicas como sujeito de

1 Bíblia sagrada, livro de gênesis, capítulo 3, versículo 7. 
direito, sendo estes direitos absolutos por serem opostos a todos, também gerais porque são inerentes a todos, extrapatrimoniais por não possuírem efeitos diretamente pecuniários, e também indisponíveis, porque o indivíduo não pode dispor deles, sendo ainda impenhoráveis e vitalícios, porque acompanham a pessoa por toda a vida (BITTAR, 2015).

Os direitos da personalidade não podem em seu exercício sofrer limitação voluntária, ou seja, ninguém poderá por ato voluntário dispor de sua privacidade ou renunciar a liberdade. Os direitos da personalidade são relativos à moral da pessoa, fundamentam a sua existência digna, tratam da integridade do corpo, da imagem, da privacidade e do nome, tutelam não apenas o afetado, mas toda a sua família em evento de morte.

A personalidade nada mais é que um atributo jurídico conferido ao ser humano e as pessoas jurídicas, em virtude da qual se tornam capazes podendo ser titulares de direitos e obrigações nas relações jurídicas. Os direitos da personalidade derivam da personalidade e a ela conferem significado, pode-se dizer que é um atributo ou valor jurídico que dá a um ser status de pessoa, sendo este direito adquirido pela simples condição humana (FIUZA, 2021).

São direitos inerentes à pessoa, ligados à essência e à dignidade humana. Encontram-se codificados na Constituição Federal como sendo o direito à própria vida, à liberdade e À manifestação do pensamento. São direitos essenciais privados que devem ser respeitados para garantir a existência e a convivência dos seres humanos (BRASIL, 1988).

Toda pessoa adquire personalidade no seu nascimento com vida e permanece por toda a sua existência, que só se perde com a morte, exaurindo-se com a exalação do último sopro vital. No entanto, alguns direitos dessa categoria, como os direitos ao corpo, ou à parte do corpo, à imagem, e o direito à privacidade permanecem post mortem.

\section{DIREITO À PRIVACIDADE E A PROTEÇÃO DOS DADOS SENSÍVEIS}

O direito à privacidade está ligado diretamente ao direito da personalidade humana, e ao tratar da privacidade no ambiente virtual, fala-se da proteção dos chamados dados sensíveis, que são conceituados como aqueles que possuem informações no qual o titular não deseja que sejam compartilhados, e que podem causar discriminação, interferindo na vida social e profissional do sujeito. A Comissão Europeia conceitua os dados sensíveis como aqueles capazes de identificar um ser humano, dados relacionados a origem racial ou étnica, opiniões políticas, convicções religiosas ou filosóficas, filiação sindical, dados genéticos, dados biométricos, dados relacionados com a saúde, a vida sexual ou orientação sexual.

Com o advento da internet foi preciso adaptar a legislação para proteger esses dados pessoais sensíveis no ambiente virtual, pois a preocupação com a privacidade aumentou devido ao uso de aplicativos e redes sociais. Ao colocar demasiadas 
informações nas redes sociais à privacidade é ameaçada, pois se cria verdadeiros arquivos de informações de cada usuário, com os mais diferentes dados sobre o seu comportamento social, econômico e pessoal.

O avanço da tecnologia aumenta o risco potencial da utilização abusiva dessas informações, e acentua a vulnerabilidade do direito à privacidade, pois os impactos decorrentes deste afetaram profundamente os modos de organização das relações sociais e as condições da realização de valores básicos das sociedades modernas (GONÇALVES, 2003).

Neste contexto, pode-se afirmar que o direito à privacidade foi o que mais sofreu mudanças devido à chegada da tecnologia. Assim, com o objetivo de proteger a privacidade e os dados sensíveis dos usuários da internet surgiu a Lei $\mathrm{n}^{\circ}$ 13.709/2018, conhecida como Lei Geral de Proteção de Dados (BRASIL, 2018). O objetivo da Lei é estabelecer regras para aqueles que coletam, armazenam e compartilham dados pessoais de terceiros para que assim, o cidadão tenha mais controle sobre o tratamento que é dado às suas informações pessoais.

A Lei visa proteger o direito à privacidade e apresenta dispositivos importantes para coibir a coleta indevida de dados pessoais, pois diariamente os indivíduos desnudam a sua intimidade ao interagir com amigos, conhecidos e desconhecidos, nos mais variados tipos de aplicativos e mídias sociais. Ela confere ao titular dos dados o direito de apropriar-se de suas informações e controlá-las, bem como define as situações nas quais pode haver a coleta e tratamento de dados desde que haja consentimento do titular de forma clara e explícita, sempre com uma finalidade determinada, conforme as hipóteses elencadas no artigo 11 da referida Lei.

Em suma, a Lei Geral de Proteção de Dados sistematizou a proteção às informações de dados pessoais e de dados pessoais sensíveis, pois a proteção destes dados abrange a proteção da privacidade e do livre desenvolvimento da personalidade. A finalidade da Lei é completar as lacunas e as dúvidas quanto aos conceitos e a abrangência da proteção de dados no Brasil, inclusive em relação às questões envolvendo o Poder Público. As medidas impostas são necessárias tanto dentro do mundo virtual como fora dele para que os direitos da personalidade não sejam violados, bem como para prevenção à fraude e à segurança do titular.

\section{DIREITO À PRIVACIDADE NO ROL DOS DIREITOS HUMANOS FUNDAMENTAIS}

Diante das infindas inovações tecnológicas e a valorização do produto informação, tornou-se muito mais fácil ter acesso a informações privadas e divulgá-las, o que aumentou os riscos de um indivíduo ter a sua privacidade violada também no âmbito virtual, pois as inovações da tecnologia possibilitam aos bancos de dados a sistematização de um grande volume de informações.

Os primeiros textos legais a proteger o direito à privacidade foram a Declaração Americana dos Direitos e Deveres do Homem aprovada na cidade de Bogotá em 1948 (ASSEMBLEIA GERAL DAS NAÇÕES UNIDAS, 1948), a qual é conside- 
rada o primeiro acordo internacional sobre direitos humanos. Dispõe o seu artigo 12 que ninguém sofrerá intromissões arbitrárias na sua vida privada, o que demonstra que o direito à privacidade já se infere como um direito humano e fundamental, pois visa proteger os predicados da personalidade humana.

Outro texto legal que visa proteger a privacidade é o Pacto Internacional dos Direitos Civis e Políticos, o qual preceitua em seu artigo 17 (BRASIL, 1992) que ninguém será objeto de intervenções arbitrárias ou ilegais na sua vida privada ou atentados ilegais à sua honra e à sua reputação. Neste sentido o autor André de Carvalho Ramos (2017) leciona que os direitos humanos consistem em um conjunto de direitos considerado indispensável para uma vida humana pautada na liberdade, igualdade e dignidade. Os direitos humanos são os direitos essenciais e indispensáveis à vida digna.

Sendo assim, o direito à privacidade insere-se dentro do rol dos direitos humanos, pois tem como premissa proteger a intimidade diante dos novos e constantes avanços da tecnologia, em que a circulação de dados virtuais se tornou instantânea e a fiscalização destes muito complicada, de maneira que a privacidade das comunicações virtuais se tornou celeremente um novo foco no desenvolvimento dos direitos da personalidade.

No dia 18 de dezembro de 2013, a Assembleia Geral das Nações Unidas aprovou a resolução 69/166 intitulada "direito à privacidade na era digital", a organização salientou que o direito à privacidade digital é um direito humano agudamente ponderoso e de proteção premente, sendo este uma ramificação dos direitos humanos que emerge como um direito básico do indivíduo, merecedor de proteção, pois todos os dias as pessoas desvelam a sua intimidade on-line, por meio de troca de arquivos e adesão a redes sociais, onde revelam uma larga fatia de suas vidas (GRAIEB, 2009).

O uso inadequado dos dados disponíveis nos mais variados tipos de plataformas digitais pode gerar inúmeros prejuízos ao seu titular. Desse modo, com o objetivo de regulamentar o tratamento de dados pessoais dos indivíduos assegurando os direitos fundamentais concernentes à proteção da liberdade, privacidade e intimidade, devido ao advento da internet, uso de redes sociais e aplicativos, tem-se a Lei Geral de Proteção de Dados, que visa proteger o direito à privacidade, dispondo sobre o tratamento de dados pessoais, inclusive nos meios digitais, por pessoa natural ou por pessoa jurídica de direito público ou privado, a fim de que o direito à privacidade, como sendo um direito humano, seja tutelado. Para que, assim, a liberdade na troca de dados dentro da rede mundial de computadores não venha a lesar a honra, a imagem e a privacidade do indivíduo.

A proteção da privacidade é uma forma de proteção da dignidade da pessoa humana e representa o ápice da tutela da vida íntima do indivíduo, que deve ser preservada, pois faz parte do desenvolvimento humano. Ao tratar da privacidade como um direito humano e fundamental deve-se levar em conta que este é, também, um direito de personalidade, uma vez que é pautado nos princípios da dignidade da pessoa humana. 
A Constituição Federal de 1988 contempla um vasto rol de direitos fundamentais. O título II da Constituição intitulado como "Dos Direitos e Garantias Fundamentais" é segmentado em cinco capítulos que dispõem sobre direitos individuais, coletivos, direitos sociais, da nacionalidade, dos direitos políticos e dos partidos políticos, constituindo do artigo $5^{\circ}$ ao $17^{\circ}$ os direitos inerentes ao ser humano. $\mathrm{O}$ direito à privacidade encontra-se disposto no artigo $5^{\circ}$, inciso $\mathrm{X}$, o qual estabelece que são invioláveis a intimidade, a vida privada, a honra e a imagem das pessoas (BRASIL, 1998).

A concreção da privacidade como um direito fundamental no ordenamento jurídico brasileiro, se dá com a Constituição de 1988. No entendimento de Pedro Lenza (2005), pelo simples fato de a positivação do direito à privacidade estar disposta na Constituição Federal isso já lhe confere o status de direito fundamental. A própria Constituição estabelece que os direitos fundamentais das pessoas não são apenas aqueles que ela enumera, mas sim tudo o que estiver de acordo com o regime político do país e com os princípios adotados pela Constituição.

Destarte, a privacidade é um direito fundamental positivado na Constituição, inerente ao ser humano e integrante da concepção da dignidade humana, sendo considerado um direito de personalidade, que representa a liberdade do indivíduo em não permitir a intromissão de estranhos em sua vida privada, podendo se opor tanto à coletividade quanto ao Estado na defesa de tais direitos (BASTOS; MARTINS, 1989).

Ademais, o direito à privacidade está diretamente ligado com a proteção dos dados pessoais tratados por meio eletrônico, sendo a proteção destes é extremamente relevante, porque a privacidade é reconhecida como direito fundamental em praticamente todos os tratados e convenções internacionais de direitos humanos ratificados pelo Brasil (LEONARDI, 2012).

A própria Lei Geral de Proteção de Dados (2018) aponta em seu artigo $2^{\circ}$ os fundamentos e a importância de proteção do direito à privacidade, como sendo um direito fundamental ao livre desenvolvimento da personalidade humana. Desta forma resta demostrada que a privacidade é um direito humano, visto se constituir em um valor indubitavelmente importante, solidificado no ordenamento jurídico, sendo indispensável à dignidade da pessoa humana, cabendo ao indivíduo que teve lesão a esse direito buscar reparação.

\section{NOÇÕES GERAIS SOBRE O DIREITO À HERANÇA NO ORDENAMENTO JURÍDICO BRASILEIRO}

A herança é conceituada como um conjunto de bens, direitos e obrigações deixados pelo de cujus aos seus sucessores. É o patrimônio ativo e passivo deixado pelo falecido, o qual é transmitido em razão da causa mortis. Para o direito Brasileiro a herança é o objeto da própria sucessão, sendo esta um complexo unitário transmitido aos herdeiros no exato momento da morte do titular.

Nos ensinamentos de Maria Helena Diniz (2021) a herança é o patrimônio do falecido, ou seja, o conjunto de direitos e deveres que se transmite aos herdeiros le- 
gítimos ou testamentários, salvo se forem personalíssimos ou pertinentes à pessoa do de cujus. Maria do Céu Pitanga Pinto (2006) dispõe existir o direito de herança em praticamente toda sociedade juridicamente organizada, em razão da necessidade de transmissão dos bens obtidos em vida pelo falecido. Essa transmissão ocorre a título universal, como direito indivisível, independente da quantidade de herdeiros, conforme dispõe o artigo 1.791 do Código Civil (2002).

A herança é abordada dentro do tema Direito das Sucessões que trata da transmissão de bens e direitos de um indivíduo, os quais após a sua morte são transmitidos para seus herdeiros. O Direito das Sucessões é o conjunto de princípios jurídicos que disciplinam a transmissão do patrimônio de uma pessoa que morreu a seus sucessores (RODRIGUES, 2007). Carlos Maximiliano (1942) define o Direito das Sucessões em dois sentidos, sendo em sentido objetivo o conjunto das normas que regulam a transmissão dos bens e obrigações em consequência da sua morte. E no sentido subjetivo, o direito de suceder, de receber o acervo hereditário do falecido.

É desta forma que os herdeiros dão continuidade na manutenção da imagem e da atuação do morto via relação sucessória. Em sentido amplo pode-se dizer que a sucessão nada mais é que o ato pelo qual uma pessoa assume o lugar de outra, substituindo-a na titularidade de determinados bens.

A herança é, na verdade, o somatório dos bens e dívidas, créditos, débitos, dos direitos e das obrigações, das pretensões e ações de que era titular o falecido, e que são transmissíveis. A partir do momento da morte do titular abre-se a sucessão, transmitindo-se automaticamente a herança aos herdeiros legítimos e testamentários do de cujus.

Eduardo de Oliveira Leite (2003) preleciona que diante da impossibilidade em se admitir que um patrimônio permaneça sem titular, o direito sucessório impõe, mediante uma ficção jurídica, para que se transmita a herança, garantindo a continuidade na titularidade das relações jurídicas do falecido por meio da transferência imediata da propriedade aos herdeiros.

Para que a sucessão seja aberta é necessário que o titular tenha falecido e que haja prova real de seu falecimento, mediante atestado de óbito, e que lhe sobrevivam herdeiros. Na falta destes, será a herança recolhida pelo Município, pelo Distrito Federal ou pela União.

Há situações nas quais embora haja evidência da morte, não é possível encontrar o corpo do de cujus, o que impossibilita o fornecimento do atestado de óbito, bem como o registro deste. Nestes casos tem-se a hipótese de morte presumida. Segundo Zeno Veloso (2003), a morte a abertura da sucessão e a transmissão da herança ocorrem num só momento, desta forma os herdeiros, por essa previsão legal, tornam-se donos da herança, mesmo que não saibam que o autor da sucessão morreu, ou que a herança lhes foi transmitida

Com a abertura da sucessão pela morte do de cujus, nasce o direito de herdar, não importa para que herdeiro. $\mathrm{O}$ direito à herança alcançou a categoria de direito fundamental e está disposto no art. $5^{\circ}$ da Constituição Federal de 1988, trata-se de uma cláusula pétrea, conforme dispõe o art. 60 , $§ 4^{\circ}$, IV. 
O Direito Sucessório, ao mesmo tempo em que visa proteger o patrimônio do falecido, visa também proteger a família como herdeira de tais bens. E ao longo da história vem este enfrentando desafios, os quais são impostos pela vida multiconectada, que impõe a necessidade de garantir a aplicabilidade das normas do Direito Sucessório ao patrimônio digital, pois é tarefa deste guiar o caminho desse acervo moderno rumo aos seus novos titulares, visto ser por meio da sucessão que se estabelece a ordem de vocação hereditária, em prol do fundamento principal do Direito das Sucessões, qual seja a continuidade da pessoa.

\section{ORIGEM E CONCEITO DA SUCESSÃO DIGITAL}

O direito das sucessões no âmbito virtual originou-se através da interação humana no meio digital, onde um grande banco de dados pessoais foi surgindo em caráter on-line. A partir das plataformas digitais os indivíduos obtém conhecimento em fração de segundos, pois podem comunicar-se, compartilhar dados, armazenar arquivos, efetuar compras on-line, compartilhar informações, opiniões e pensamentos com qualquer um que esteja conectado à rede mundial de computadores.

Aos poucos, todos esses rastros de informações vão se acumulando na nuvem e geram um denso patrimônio na esfera digital. Com isto, surge a necessidade de transmissão deste patrimônio após a morte de seu titular, pois todo o legado digital de um indivíduo que fica disponível na nuvem ou armazenado em um computador logo após sua morte faz parte de sua herança digital. Todas as informações guardadas em formato de arquivo nos mais variados dispositivos eletrônicos, como computadores, pen drives e celulares, também podem ser consideradas componentes desse acervo moderno (SILVA, 2014).

O patrimônio digital abarca todos os dados pessoais, é um conjunto de informações acerca de um usuário que se encontra em formato digital. Todas estas informações constituem-se em um complexo de bens e relações jurídicas de conteúdo econômico e sem suscetibilidade de análise econômica, que recebem proteção direta ou indireta do ordenamento brasileiro.

Os bens digitais que possuem valor econômico podem ser objeto da herança digital, sendo estes transmissíveis aos herdeiros. Em relação aos bens sem valor econômico resta dúvida, pois a possibilidade de transmissão ou acesso ao conteúdo podem violar os direitos da privacidade. Por isto, a possibilidade de transmissão ou acesso a conteúdo deve ter como baliza norteadora a privacidade do de cujus e de terceiros com quem o usuário falecido mantinha contato.

A herança digital difere da herança tradicional expressa no Código Civil (2002), pois esta abarca não só a transferência de bens, mas também o acesso a conteúdo e informações. A herança, quando transmitida aos herdeiros, inclui um emaranhado de relações jurídicas dotadas de valor econômico de uma determinada pessoa, infere-se que arquivos digitais dotados de tal valor (sites, músicas, filmes, livros, bens virtuais etc.) devem também fazer parte da partilha. A relevância destes bens digitais facilita a interferência destes na parcela legítima reservada aos herdeiros (ROHRMANN, 2005). 
A sucessão digital tende a aprazer a realidade da população virtual. Jaime Gustavo Gonçalves de Oliveira (2015) dispõe que, nos últimos anos, o tema de Gestão da Herança Digital tem despertado a atenção de inúmeros investigadores, uma vez que a par duma vida real, muitos de nós têm uma vida paralela, fruto das inovações tecnológicas e da crescente utilização das novas tecnologias, que é a vida digital.

Paralelamente os indivíduos têm uma vida que caminha conjuntamente a si, fruto da crescente utilização das novas tecnologias por meio do uso de aplicativos e mídias sociais, bem como da aquisição de bens no meio virtual, pois tal qual na vida real, na vida digital possuem-se bens ou objetos de valor. No entanto, são bens em formato digital e propriedades digitais de cada um, os quais estão presentes no cotidiano, seja pela transmissão de mensagens, armazenamento de fotos nas plataformas de nuvens, ou por meio de itens adquiridos na modalidade on-line, com valor econômico como as coleções de músicas nos aplicativos de Itunes, os jogos em servidores como o Steam, os filmes adquiridos no Google Play e os livros adquiridos na Amazon.

São sem dúvida bens jurídicos, já que podem ser objetos de uma junção jurídica. Os bens digitais, quanto à sua concretude, devem ser classificados como espécies de bens incorpóreos, ou seja, aqueles com existência abstrata e que não podem ser tocados pela pessoa humana, razão pela qual é merecida a proteção jurídica para os arquivos digitais, até mesmo pelo fato da função social da sucessão impedir que um patrimônio permaneça sem titular.

\section{SUCESSÃO DE BENS ARMAZENADOS VIRTUALMENTE}

Com o avanço tecnológico, surgiu a busca de uma viabilidade jurídica em reconhecer os bens armazenados virtualmente como componentes do patrimônio de um sujeito. Até o presente momento não há uma legislação vigente que trata exclusivamente desse fenômeno na esfera dos bens digitais. Porém, os projetos de Lei n. 4.099/2012 (BRASIL, 2012) e 7.742/2017 (BRASIL, 2017) mencionam em seu conteúdo a relevância do tema e a preocupação pelo enquadramento no Direito Sucessório, já que este é o cerne de transferência patrimonial em razão da morte de um indivíduo.

A herança digital busca adequar o Direito Sucessório à realidade da imersão virtual, para assim viabilizar o reconhecimento de bens virtuais como parte de um patrimônio, e consequentemente, a transmissão deste. Como a sucessão de bens digitais não é proibida no Brasil, é garantido o direito da herança digital por que não existe qualquer expressão positiva que proíba o referido instituto (LARA, 2016).

Em harmonia com a referida ideia Medina (2011) também defende que diante da ausência de direito positivado no Brasil a respeito da matéria, há uma espécie de permissão negativa para tal, ancorado no princípio da legalidade. O PL 4.847 de 2012 estabelece normas de herança digital, na qual dispõe que se o falecido, tiver capacidade para testar, e não o tiver feito, a herança será transmitida aos herdeiros 
legítimos. E neste caso os herdeiros podem definir o destino das contas, podendo transformá-las em memorial, no caso das redes sociais, nas quais o acesso fica restrito a amigos confirmados e mantém apenas o conteúdo principal, ou podem apagar todos os dados do usuário, bem como remover a conta do antigo usuário (RICARTE; MANZEPPI, 2020).

Em regra, os direitos sobre os bens armazenados virtualmente, advindos da sucessão, ficam com os familiares mais próximos do falecido, como filhos, pais, cônjuges ou com os legatários, através de testamento, conforme preleciona o artigo 1.784 do Código Civil (GONÇALVES, 2017).

Os bens armazenados virtualmente em hard drives de propriedade do falecido são facilmente transferíveis, pois acompanham a mídia tangível, ou seja, o hardware herdado. Desta forma, as fotos ou textos armazenados em pastas virtuais não são tão diferentes dos bens corpóreos, palpáveis. Entretanto, são parte crescente do patrimônio digital, composto por arquivos adquiridos ou armazenados em servidores on-line, cujas regras de transferência e acesso acabam sendo ditadas pelos próprios provedores.

$\mathrm{Na}$ falta de legislação que regulamente o tema, os arquivos armazenados virtualmente em contas de e-mails ou redes sociais têm sua transmissão regida exclusivamente por termos de serviços. É o caso, por exemplo, de Facebook, Twitter, Instagram e Google que propõem suas próprias soluções no que se refere à sucessão do patrimônio digital.

Desde 2009 o Facebook começou a tratar sobre a "morte virtual" de seus usuários, devido ao fato de um empregado ter proposto a criação de um "memorial", após a morte de um ente próximo. Atualmente os usuários do Facebook podem informá-lo que no caso de sua morte pretende que seu perfil seja excluído ou transformado em um memorial sobre a administração de um contato herdeiro. Entretanto, caso o usuário falecido não tenha optado por nenhuma das alternativas os herdeiros poderão fazê-lo mediante a comprovação de óbito e parentesco (FACEBOOK, 2021).

Já o Twitter permite que uma pessoa autorizada aja em nome do Estado ou da família para desativar a conta. A pessoa autorizada faz uma solicitação, então o Twitter envia um e-mail com instruções para fornecer mais detalhes sobre a pessoa falecida, bem como uma cópia de sua identidade e uma cópia da certidão de óbito. O site deixa claro que é possível a desativação da conta, mas não podem ser fornecidas nenhuma informação de acesso a conta, independentemente do tipo de relacionamento com a pessoa falecida (TWITTER, 2021).

O Instagram permite que qualquer pessoa que souber do falecimento de um usuário faça a denúncia. Para que a denúncia seja válida é necessária a comprovação do óbito, que pode se dar por meio de um artigo em jornal, comprovado o óbito a conta é transformada em memorial e apenas os parentes podem solicitar que a conta seja removida da plataforma. O Instagram deixa claro que acessar a conta de outra pessoa vai contra suas políticas, assim, as informações de acesso não podem ser divulgadas (INSTAGRAM, 2021). 
A Google oferece aos seus usuários a funcionalidade "gerenciador de contas inativas", opção que permite aos usuários que possuem conta em qualquer um de seus produtos informar previamente quem deverá ter acesso as suas informações, ou se deseja que sua conta seja excluída em caso de falecimento ou acidente.

Caso o usuário não utilize a conta por um tempo a Google entra em contato, através de e-mail ou SMS e não obtendo resposta do usuário as suas configurações de "conta inativa" são ativadas. Sendo a conta considerada inativa, a Google notifica as pessoas indicadas pelo usuário, podem ser até 10 pessoas, que podem ter acesso às informações determinadas pelo usuário. A partir deste momento é possível realizar a transferência do conteúdo digital pertinente ao falecido. Se o usuário optou pela exclusão de sua conta, as pessoas indicadas terão prazo de três meses pra transferir o conteúdo autorizado (GOOGLE, 2021).

Observa-se que estas redes sociais já definiram as suas próprias políticas para tratar da sucessão dos bens virtuais, entretanto, ainda existem diversas dúvidas quanto à sucessão de alguns patrimônios virtuais, tais como as moedas virtuais e as milhas aéreas. As moedas virtuais utilizam a tecnologia blockchain, e os herdeiros podem acessá-las mediante a chave de acesso do falecido, no entanto esta não tem uma política de transferência do patrimônio. Da mesma forma, as milhas aéreas também não tratam da política de transferência, mesmo que possuam potencial econômico devendo ser permitida a sua transmissibilidade.

\section{CLASSIFICAÇÃO DOS BENS DIGITAIS}

Os bens digitais podem ser classificados como suscetíveis de valoração econômica ou insuscetíveis de valoração econômica. No que se refere aos bens suscetíveis de valor econômico, cabe mencionar as músicas, vídeos, bibliotecas digitais, jogos on-line, moedas virtuais, milhas aéreas, e até mesmo aquelas redes sociais que, em alguns casos, os usuários passaram a utilizar como um meio para obter renda. Esses bens possuem características patrimoniais e podem ser transmitidos aos herdeiros quando acontecer o falecimento do usuário.

Assim, os bens digitais de valor econômico devem ser considerados como patrimônio hereditário, e ter os mesmos efeitos jurídicos que o patrimônio físico deixado pelo de cujus a título de herança. Ademais, por se tratarem de bens digitais de natureza patrimonial, poderão ser administrados, bem como sofrer divisão, segundo as regras sucessórias previstas no art. 1.845 e seguintes do Código Civil (2002), vez que possuem valor econômico, geram direitos hereditários e, portanto, compõem a herança digital a ser partilhada.

Já os bens insuscetíveis de valoração econômica são aqueles de valor sentimental, como as fotos, vídeos, as mensagens enviadas por e-mail e os recados inbox nas mídias sociais, entre outros conteúdos que estão ligados à personalidade e à existência de seu titular, não sendo estas relações apreciáveis economicamente.

Desta forma, a conta de um usuário na rede social sem intuito econômico não 
deve ser considerada como patrimônio, por estar esvaziada de valor econômico contendo apenas um valor sentimental, que acarreta a impossibilidade de transmissão destes bens digitais ligados à existência, sem a manifestação de vontade do de cujus, ante a intransmissibilidade dos direitos da personalidade.

Lacerda (2017) os classifica, ainda, como sendo bens incorpóreos, inseridos por usuário de forma gradativa na internet, informações de caráter pessoal que tenham alguma importância e utilidade para si, que contenham ou não conteúdo econômico.

Assim, para que seja resguardada a vontade individual de transmissão desses bens, de acordo com a legislação atual, seria por meio do codicilo, instrumento que não exige solenidades, sendo necessário estar datado e assinado, ou dos cofres virtuais, por meio destes o usuário pode evitar a transmissão de seus bens virtuais.

\section{COLISÃO ENTRE DIREITOS FUNDAMENTAIS: DIREITO À PRIVA- CIDADE VERSUS DIREITO À HERANÇA}

Sem uma legislação específica a herança digital vem causando enorme repercussão. Há vários julgados em que mães entraram na justiça pedindo para ter acesso à conta do Facebook de filho falecido. Se por um lado ela possui o direito à herança digital, de outro lado o de cujus possui o direito de não ter sua privacidade violada. Nota-se que há aqui um conflito de princípios, ou seja, há colisão entre dois direitos fundamentais.

Novelino (2014) entende que para ser solucionada esta colisão pode ser utilizada a técnica da ponderação, a qual é dividida em três etapas que consistem na identificação das normas e seu agrupamento conforme a direção para a qual apontam. Posteriormente, devem ser analisadas as circunstâncias do caso concreto e suas repercussões. Após essas duas etapas preparatórias, deve-se atribuir o peso relativo aos elementos e estabelecer a intensidade da preferência de cada grupo de normas.

Considerando ambos os direitos possuírem amparo constitucional, caberá ao intérprete levar em conta qual dos referidos princípios garante de forma mais satisfatória a dignidade da pessoa humana, visto esta encontrar-se expressa na Constituição de 1988, levando ao entendimento de que a tutela estatal deve ser exercida em favor do ser humano.

Segundo o entendimento de George Marmelstein (2008) nestes casos o jurista terá que conciliar ou harmonizar os interesses em jogo, pelo princípio da concordância prática. Somente depois, caso não seja possível a conciliação, é que se deve partir para a técnica da ponderação propriamente dita.

Gilmar Mendes (2012) aponta ainda que os conflitos ocorridos entre direitos fundamentais devem ser analisados sob o prisma do princípio da dignidade humana, por ser este de grande importância em nosso ordenamento jurídico. Lacerda (2017) defende que a dignidade da pessoa humana não seria um simples direito e garantia fundamental, mas sim um guia para a aplicação de toda a ordem constitucional, havendo a supremacia deste princípio em relação aos de igual hierarquia. 
É meritório relembrar que o direito à privacidade é garantido pela Constituição Federal (1988), através dos direitos da personalidade, desta forma a colisão entre os princípios deve ser solucionada de acordo com o Princípio da Dignidade da Pessoa Humana, pois a aplicabilidade das normas do Direito Sucessório ao patrimônio digital não deve afetar direitos individuais, como por exemplo, o direito à privacidade.

Posto isto, para que não haja carência de proteção por parte do direito, deve ser utilizada a técnica da ponderação, conjuntamente com o Princípio da Dignidade Humana, em que deverá ser analisada a questão da privacidade e o direito de herdar dos sucessores.

Atualmente no Brasil uma das redes sociais mais utilizada é o Facebook, segundo dados coletados no site Eixo Digital (2021) a rede social possui cerca de 2,4 bilhões de usuários ativos por mês, sendo 129 milhões de brasileiros, o que corresponde a $59 \%$ de todo o acesso da população brasileira nas redes sociais. Nesta rede social os indivíduos interagem e conversam com outros, compartilham suas experiências e histórias tornando o ambiente público, mas ao mesmo tempo íntimo.

Neste ambiente as pessoas curtem, fazem comentários e conversam com amigos e conhecidos pelo bate-papo, sendo estas conversas privadas e ligadas à proteção dos direitos da personalidade, sendo este a privacidade, a intimidade e a honra. Tudo o que a pessoa faz no Facebook gera um arquivo digital e quando vem a falecer esses arquivos são transferidos por meio de um "testamento digital" a um familiar ou terceiro previamente autorizado que poderá fazer o gerenciamento da conta do falecido (SANZI, 2018).

Assim, não se afigura razoável privar o herdeiro da sucessão do Facebook se o próprio usuário determinou em vida sobre quem seriam os seus herdeiros responsáveis pelo gerenciamento da conta. No entanto, se o de cujus não definiu os herdeiros em vida, a transmissão deste deve ter como baliza norteadora o direito de privacidade do de cujus.

Todavia, ainda não há na legislação brasileira uma resposta clara se esses dados digitais constituem ou não em patrimônio possível de ser herdado. Tanto o direito à privacidade quanto o direito à herança estão ligados a dignidade da pessoa humana, e ao sopesar os princípios deve-se levar em conta o direito à privacidade.

\section{O FACEBOOK COMO UM BEM DIGITAL: DIREITO À HERANÇA OU DIREITO À PRIVACIDADE?}

Sabe-se que os bens virtuais são bens intangíveis, aqueles adquiridos, recebidos, produzidos ou desenvolvidos no meio digital, guardados ou acumulados no espaço virtual, tal como o Facebook. Muito se discute sobre a possibilidade de este integrar o patrimônio do de cujus e posteriormente ser transferido a título de herança.

Todavia, um dos problemas iniciais enfrentados em relação a transferência do acesso ao perfil do usuário falecido pelos herdeiros relaciona-se ao próprio enquadramento jurídico das informações contidas nesta rede social, pois muitas infor- 
mações são de cunho pessoal, e a partir do momento da sucessão e acesso ao perfil do usuário a privacidade do de cujus estaria sendo violada.

No entanto, no contexto dessa rede social, a experiência do luto também passa por um processo de transmutação, pois os amigos e familiares acabam por conviver com o conteúdo que o falecido inseriu e deixou na rede. A internet, em muitos casos já passou a ser um espaço de ritualização post mortem, já havendo, inclusive, cemitérios digitais com memoriais de pessoas falecidas. O site Find a Grave (2021), por exemplo, é uma espécie de site de busca pelo qual o visitante pode localizar túmulos virtuais, com dados diversos e fotos da pessoa falecida, podendo até mesmo, enviar flores a ela.

Apesar disso, há uma grande preocupação quanto à transmissibilidade ou não do conteúdo disposto na rede no que se refere aos dados pessoais sensíveis do usuário falecido, pois não se pode ignorar que alguns direitos são personalíssimos, e, portanto, intransmissíveis, extinguindo-se com a morte do titular, não sendo objeto de sucessão, não integrando o acervo sucessório por ele deixado (CARVALHO, 2015).

Do mesmo modo que a herança se refere ao acervo patrimonial deixado pelo de cujus, há situações existenciais, resguardadas as situações dúplices em alguns pontos, não vão integrar o conceito de herança. Assim, é importante que se entenda essa diferenciação, pois o tratamento estritamente patrimonial é insuficiente para deslindar todos os problemas que decorrem da morte do usuário (MEIRELES, 2009).

Ana Luiza Maia Nevares (2009) destaca que adquirir determinado direito pode acontecer por ocasião da morte sem que isso signifique que há sucessão, o que se aplica no caso das situações jurídicas extrapatrimoniais pertencentes ao de cujus. A doutrinadora destaca ainda que nesses casos, os sucessores ou as pessoas designadas pelo legislador adquirem o direito de agir diante das mesmas causa mortis, ou seja, em virtude do falecimento de seu titular originário. No entanto, não significa que o direito que antes pertencia ao falecido é adquirido pelos sucessores em razão da natureza das referidas situações.

O direito brasileiro entende que a morte é a medida da personalidade civil da pessoa humana, sendo o direito à privacidade uma espécie dos direitos da personalidade, e desta forma, mesmo que haja o fim da personalidade com a morte física do usuário não significa que determinado direito vinculado à pessoa do de cujus deixa de receber proteção jurídica, portanto, mesmo após a morte do titular, a personalidade, considerada valor, ainda pode ser objeto de tutela no ordenamento jurídico (TEPEDINO, 2004).

Desta forma, não há que se falar em transmissão post mortem dos direitos da personalidade, e sim da tutela de proteção aos direitos da personalidade, que engloba o direito de privacidade do de cujus. Assim, os dados pessoais dos usuários falecidos não podem ser transferidos aos herdeiros, tendo em vista que se referem a aspecto existencial do de cujus. E permitir que a privacidade da pessoa falecida seja devassada pelos familiares, mediante acesso irrestrito à sua conta do Facebook 
e seus dados ali contidos viola um de seus direitos da personalidade, que seria o direito à privacidade.

Em sentido semelhante Anderson Schreiber (2014) defende que tais direitos da personalidade não seriam "coisas" transmissíveis por herança. Portanto, o acesso aos dados privados no perfil do Facebook de usuário falecido não faz parte da herança, e sim da tutela post mortem de proteção aos direitos da personalidade.

Outrossim, nem todo o acervo patrimonial do de cujus deve ser transmitido a título de herança. No caso das redes sociais, como por exemplo o Facebook, mesmo sendo um bem digital, a partir do momento em que o acesso aos dados privados é transmitido aos herdeiros tem-se uma violação do direito de privacidade do antigo usuário. Os perfis em redes sociais podem sem considerados como obras pessoais, pois são criações intelectuais que exprimem as particularidades de um indivíduo, desta forma caberia aos herdeiros apenas o direito de reivindicar a autoria da obra, não sendo possível nem mesmo pleitear a exclusão do perfil do falecido.

Desta forma, a retirada do conteúdo de rede social após a morte do usuário só deve ser permitida em casos nos quais os familiares ou terceiros, que tinham relação com o de cujus, se sintam diretamente ofendidos por algum conteúdo postando fazendo referências a ele. Segundo Prinzler a exclusão do conteúdo se limita ao post, imagem ou comentário compartilhado, nunca ao perfil por inteiro, pois os perfis em redes sociais normalmente não possuem caráter patrimonial, ou seja, não são passíveis de valoração econômica, não sendo possível a transmissão do acesso (PRINZLER, 2015).

Deste modo, entende-se que não deve ocorrer a transmissão do perfil do Facebook a título de herança, salvo disposição de última vontade do titular da conta autorizando seus herdeiros a acessar seu perfil. Entretanto, se o indivíduo não o faz, deixando de indicar quem terá acesso às mensagens, fotos, vídeos ou outro material confidencial, cabe respeitar o seu direito à privacidade. Afinal, com a morte, extingue-se a personalidade, mas não a tutela de proteção a este direito.

Somente alguns interesses, em especial aqueles ligados à honra e à imagem do falecido, assim como os que podem afetar os parentes próximos, são vistos como merecedores de proteção antes de enfraquecer os direitos de personalidade. Os usuários das redes sociais possuem autonomia privada podendo decidir livremente quem pode ou não ter acesso ao legado digital armazenado de forma virtual. Com isso, prioriza-se a autonomia privada e a responsabilidade do autor do legado digital, em solução harmônica com o sistema sucessório para decidir sobre a transmissão de seu perfil aos herdeiros, já que até o presente momento não existe uma legislação que trata efetivamente sobre a transmissão dos bens virtuais.

\section{A NECESSIDADE DE REGULAMENTAÇÃO DA HERANÇA DIGITAL NO ORDENAMENTO JURÍDICO BRASILEIRO}

A expansão da internet resultou, para as relações humanas e para o mundo jurídico inúmeras mudanças sociais, atualmente a internet está incorporada à nossa 
vida de tal maneira que é quase impossível fazer qualquer coisa sem ela, ao mesmo tempo em que é impulsionadora de oportunidades, encerra em seu bojo inúmeros e indecifráveis desafios, ocasionando mudança de costumes e hábitos dos indivíduos, trazendo novas emergências ao momento atual.

É o caso da herança digital que, na contemporaneidade, não possui regulamentação específica, provocando disparidades nas decisões judiciais, visto o Código Civil (2002) não disciplinar a herança digital nos títulos destinados à parte da sucessão e os tribunais acabam julgando os casos concretos com base em normas gerais, fato este que acaba ocasionando diversas lacunas as quais, não raras vezes, necessitam ser preenchidas pelo Poder Judiciário (VIRGÍNIO, 2015).

A sociedade em rede representa uma transformação qualitativa da experiência humana ao passo que as ações sociais transformam as relações entre a cultura e a natureza, insurgindo-se neste contexto uma nova forma de estruturação da sociedade. Esta nova forma está entretecida a novas consequências jurídicas, necessitando de inovações legislativas a fim de não deixar a sociedade desamparada ante aos desafios que surgiram e continuarão surgindo em torno da herança digital (CASTELLS, 2016).

Desse modo, cabe ao direito acompanhar a evolução da sociedade em rede, pois a partir desta surgem novos institutos jurídicos, os quais devem ser regulamentados pelo ordenamento jurídico brasileiro, pois a falta de normativas específicas que regulamentam os fatos circulantes na internet, carece de uma legislação que trate efetivamente os conflitos oriundos do âmbito virtual (LIMA, 2013).

Diante da lacuna legislativa não se sabe ao certo sobre a existência ou não da herança digital, o que faz com que magistrados julguem os casos de forma diversificada. Outrossim, quando o Poder Judiciário é acionado para resolver um conflito decorrente da herança digital tem que aplicar as mesmas legislações que tratam do Direito das Sucessões, dispostas do artigo 1.784 ao 2.027 do Código Civil (2002), no entanto, este não disciplina a herança digital nos títulos que dedica ao Direito das Sucessões, o que provoca disparidade das decisões judiciais, tendo em vista que os tribunais julgam os casos concretos com base somente nas normas gerais que regem a matéria (VIRGÍNIO, 2015).

Ademais, faz-se necessária uma mudança no corpo normativo devido às novidades introduzidas pela tecnologia da informação. Para além de ser vista como adequação do Direito, essa mudança deve ser encarada como uma forma de afastar injustiças provocadas por decisões judiciais díspares. Além do mais, é o Direito quem regra a vida em sociedade, mesmo que de modo vagaroso. A norma jurídica deve ir de encontro àquilo que normalmente a sociedade já está presenciando, como é o caso da herança digital. (PRINZLER, 2015).

A regulamentação da matéria tem uma importância crucial devido ao fato de que o direito à herança é norma de ordem constitucional, garantida explicitamente na Constituição Federal (1988), bem como os direitos da personalidade, que mesmo após a morte do indivíduo ainda são objeto de tutela. Com a morte não há personalidade, mas existe uma situação jurídica que deve ser tutelada, o que torna a re- 
gulamentação da matéria improtelável, sendo primordial a criação de uma norma que garanta maior segurança jurídica, e equilibre o novo direito à herança digital, com demais preceitos fundamentais, tais como a honra, intimidade e privacidade.

\section{A INDUBITÁVEL NECESSIDADE DE INCLUSÃO DOS BENS DIGITAIS NO DIREITO SUCESSÓRIO}

Fato evidente ser o surgimento da internet um marco disruptivo que revoluciona a forma como a sociedade se relaciona, desde a esfera pessoal até a profissional, e cabe ao direito reger estas relações, se adequando às necessidades dos indivíduos. Mais especificamente, cabe ao Direito Civil reger estas relações advindas da transformação do uso da internet, pois em suas especificidades, é este que conduz todas as fases da vida de um sujeito de direito, desde sua aquisição da personalidade jurídica, até o momento post mortem, em que inicialmente abre-se uma sucessão de bens, transmitindo o acervo patrimonial deixado pelo falecido.

É o Direito das Sucessões que disciplina a transferência patrimonial de uma pessoa, em função de sua morte, desse modo, todo o conjunto de bens deixado pelo de cujus, inclusive os bens digitais, devem abarcar a herança, visto que só podem ser transferidos para outros após a morte de seu titular. Além disso, o direito de herança encontra-se disposto na Constituição Federal de 1988, como sendo um direito fundamental (GAGLIANO, 2017).

São os herdeiros que dão continuidade às relações jurídicas preexistentes adquiridas e compactuadas pelo de cujus, que não necessariamente precisam se extinguir pelo óbito. Nesta senda, é imprescindível observar que os bens virtuais também devem fazer parte da herança, assim como serem transmitidos aos herdeiros, para que estes deem continuidade nas relações jurídicas do de cujus (TARTUCE, 2017).

Os bens digitais devem fazer parte do direito sucessório justamente por constituírem o patrimônio ativo e passivo adquirido no âmbito virtual, que incorpora tudo o que o falecido deixou em vida, devendo este ser transmitido aos herdeiros, pois conforme preceitua Paulo Lôbo (2016) o direito das sucessões não é dos mortos, mas sim dos vivos, visto serem estes os reais titulares e destinatários dele.

Após a morte, então, não podem os sucessores ficarem desamparados economicamente e sem ingerência sobre o que fora deixado pelo falecido. Tal garantia, observa-se, é estendida também aos bens virtuais, já que não há como deixar de pensar em momentos póstumos, pois tanto a utilização da internet quanto a morte fazem parte da realidade.

A sociedade está passando por um processo de digitalização, e cada vez mais encontra-se submersa no mudo virtual, onde o conteúdo tornou-se um objeto de negociação, um produto, a todo instante surge um novo site ou portal vendendo conteúdo que não é gerado necessariamente para um comprador, mas torna-se cada vez mais uma mercadoria cuja posse agrega valor ao seu proprietário, sendo perfeitamente possível a inclusão desses bens digitais no Direito Sucessório (PINHEIRO, 2016). 
Embora seja difícil de distinguir os que têm o cunho patrimonial e os que não têm disposição financeira envolvida, percebe-se que há a necessidade de transmissão destes bens a título de herança, pois independente da caraterística rentável ou não do bem, os herdeiros podem querer ter acesso ao acervo digital do falecido. Além disso, a herança não precisa ser necessariamente composta por bens de valoração econômica e sim de todos os bens que o falecido deixar. Desta forma os bens virtuais compõem a herança independente de terem valor ou não, pois fazem parte do conjunto de bens deixado aos sucessores por aquele que faleceu (TARTUCE, 2017).

Além disso, é o Direito Sucessório que regulamenta a transmissão de bens, direitos e obrigações em razão da morte, tornando-se necessária a inclusão dos bens digitais no Direito Sucessório, pois o direito à herança é um direito fundamental que foi remodelado pela tecnologia, a qual alterou de forma significativa as relações humanas ao propiciar o compartilhamento de informações e a aquisição de bens no meio virtual, trazendo para o judiciário novas demandas de conflitos que até então eram desconhecidas (TEIXEIRA, 2019).

Outrossim, observa-se que a transmissão dos bens virtuais não viola os direitos da personalidade quando o próprio titular dispõe em vida sobre o desejo de transmissão dos bens, considerando-se que a morte completa o ciclo vital da pessoa humana, extinguindo a sua personalidade e, extinguindo-se a personalidade, cabe aos herdeiros a proteção do patrimônio, chamado de espólio (FARIAS, 2017).

A herança se respalda no direito de seus sucessores terem acesso aos bens do falecido, como por exemplo, os bens digitais. Deste modo, quando os familiares buscam o judiciário estão buscando mais do que a proteção prevista, que é a continuidade de manter o perfil das redes sociais ativos e requerer o direito de herdar os bens acumulados virtualmente pelo falecido. Ademais os direitos da personalidade, bem como o Direito Civil devem acompanhar a nova realidade produzida pela evolução high-tech, uma vez que, paulatinamente, o patrimônio que se forma na esfera digital acaba tendo alto valor, mesmo que virtual, já que tudo se expõe, se compra, se vende e se demonstra por meio da Internet.

Assim, não se pode desprezar no momento de partilha algum bem que esteja guardado em uma plataforma digital. Até porque, o acesso, a catalogação, a seleção e o descarte do acervo digital não são tarefas simples, pois após o surgimento da internet, passou-se a morrer de modo menos definitivo, após a morte o indivíduo acaba deixando um grande acervo digital, que inclui as criptomoedas, as coleções de e-books, músicas, filmes e games, fotografias, vídeos, mensagens e perfis em redes sociais, que juntos compõem o acervo digital do falecido (BRANCO, 2017).

O acervo digital deixado pelo falecido é todo o conjunto de bens de potencial valor econômico armazenados virtualmente ou virtuais, e podem ser abarcados pela ideia de herança, uma vez que não há restrição no ordenamento jurídico para esses bens estarem abrangidos na ideia de herança. Os arquivos digitais sem conteúdo econômico ou com conteúdo econômico que sejam projeção da privacidade de cada pessoa podem ser objeto de partilha, no entanto o falecido deve em vida fazer 
uma declaração de vontade expressa por instrumento público ou particular ou por comportamento concludente devidamente comprovado (COSTA, 2016).

Conclui-se que a problemática da transmissão dos bens virtuais não está apenas na mudança do Código Civil, mas também na importância da proteção dos dados que o falecido deixar, pois o acesso à herança digital, por vezes, esbarra no direito de privacidade do falecido, criando um conflito de princípios constitucionais.

Outrossim, faz-se evidente a necessidade de regulamentação da herança digital, haja vista que as principais plataformas digitais já possuem políticas próprias para o caso de falecimento de seus usuários. É o caso do Facebook, por exemplo, que possibilita ao usuário indicar um contato herdeiro para gerir a conta após sua morte, ou mesmo para apagá-la ou transformá-la em memorial, se for da vontade do usuário.

À vista disso, deve-se observar que nos casos de solicitação de acesso aos dados privados de bens digitais de pessoa morta, deve-se privilegiar a privacidade do de cujus, vez que o direito de privacidade prevalece sobre o direito de herança, pois este abrange os sentimentos do ser humano, que está além de questões patrimoniais.

Além do mais, deve-se levar em conta que em alguns casos a conta foi transformada em memorial, no caso das redes sociais, como Facebook, Instagram e Twitter, por disposição de última vontade do titular, tendo ele concordado com a política do site quando fez a inscrição. Além disso, o conceito de memoriais digitais deriva do conceito de memoriais existente no mundo físico, onde monumentos concretos são utilizados para simbolizar e honrar a memória de uma pessoa ou acontecimento.

Diante de toda a problemática que envolve a herança digital, há necessidade de se positivar no Direito Sucessório os bens digitais, até porque não se pode tratar todas as situações virtuais da mesma forma, pois há quem utiliza o direito à privacidade como forma de limite à transmissibilidade dos bens digitais e há aqueles que voluntariamente, abdicam de suas expectativas de privacidade e buscam retorno financeiro por meio dos bens virtuais, assim deve-se levar em conta questões de avaliação monetária e a privacidade do de cujus.

\section{CONSIDERAÇÕES FINAIS}

O avanço tecnológico trouxe para o Direito Sucessório uma nova modalidade de patrimônio, sendo este um conjunto de informações acerca de um usuário que se encontra em rede digital. Este cenário denota uma verdadeira transformação, pois impõe desafios para o Direito, passando este a se deparar com situações ainda pouco vivenciadas e reguladas.

No campo do Direito Civil há uma grande discussão sobre o que são bens digitais e sobre a viabilidade de uma herança digital, isto é, sobre a possibilidade de a sucessão universal incluir também bens digitais, pois a cada dia as pessoas passam a ter mais patrimônios digitais e isso repercute no Direito Sucessório, fazendo 
surgir inúmeros questionamentos e até mesmo demandas judiciais, nas quais os herdeiros pleiteiam sobre o direito de herdar os bens virtuais.

A questão principal consistiu-se na análise sobre a extensão dos direitos da personalidade mesmo após a morte do titular, pois conforme o Código Civil, a existência da pessoa natural termina com a morte. A conclusão a que se chegou foi de que a personalidade jurídica se finda com a morte, no entanto, a tutela de proteção aos direitos da personalidade persiste, pois a tutela post mortem dos direitos da personalidade se refere a uma espécie de extensão da vida do indivíduo, uma forma de preservação de sua memória.

À vista disso, deve se observar que a privacidade, assim como a herança, é um direito fundamental, portanto a transmissibilidade do acervo digital aos herdeiros não deve ferir o direito à privacidade, pois ao sopesar os princípios conflitantes evidencia-se que o direito à privacidade do falecido frente ao direito de herdar prevalece, com base na dignidade da pessoa humana que excede a existência física.

Neste contexto, em análise ao direito das sucessões conclui-se que é necessária a regulamentação da herança digital no ordenamento jurídico brasileiro, bem como a inevitabilidade da inclusão dos bens digitais no Direito Sucessório, visto que os bens virtuais de valoração econômica devem ser imediatamente transmitidos aos herdeiros da mesma forma que os bens não virtuais, já que a herança também é direito fundamental.

Por fim, conclui-se que o tema é complexo e multifacetado, pois une a um só tempo duas dimensões distintas do Direito Civil, sendo a regulação de situações subjetivas patrimoniais, que acarreta efeitos em situações subjetivas existenciais. Assim, para que os conflitos possam ser dirimidos se faz imprescindível a regulamentação na legislação, bem como a compreensão de todas as dimensões da problemática em comento, abarcando o direito à personalidade, e a proteção de dados pessoais, não permitindo que a transmissão dos bens digitais abarque o acesso aos dados privados de usuário falecido.

\section{REFERENNCIAS}

ASSEMBLEIA GERAL DAS NAÇÕES UNIDAS. Declaração Universal dos Direitos Humanos. Disponível em: https://www.uc.pt/protecao dedados/legis/declaracao_americana_de_direitos_e deveres_do_homem. Acesso em: 25 nov. 2021.

BASTOS, Celso Ribeiro; MARTINS, Ives Gandra. Comentários à Constituição do Brasil. São Paulo: Saraiva, 1989.

BITTAR, Carlos Alberto. Os direitos da personalidade. 8. ed. São Paulo: Saraiva, 2015.

BRANCO, Sérgio. Memória e esquecimento na internet. Rio de Janeiro: Arquipélago Editorial, 2017.

BRASIL, Constituição da República Federativa do Brasil de 1988. Disponível em: http:// www.planalto.gov.br/ccivil_03/Constituicao/Constituicao.htm. Acesso em: 30 jun. 2021. 
BRASIL, lei $\mathbf{n}^{\mathbf{0}}$ 13.709, de 14 de agosto de 2018. Disponível em:http://www.planalto.gov. br/ccivil_03/_ato2015-2018/2018/lei/113709.htm. Acesso em 25 nov. 2021.

BRASIL, Decreto no 592, de 6 de julho de 1992. Disponível em: http:/ / www.planalto.gov . br/ccivil_03/decreto/1990-1994/d0592.htm. Acesso em 25 nov. 2021.

BRASIL, Câmara dos Deputados. Projeto de Lei $n^{\circ} 4099$, de 26 de junho de 2012. Altera o art. 1.788 da Lei $n^{\circ}$ 10.406, de 10 de janeiro de 2002, que "institui o Código Civil. Disponível em: https:// www.camara.leg.br/proposicoesWeb/fichadetramitacao?idProposi$\underline{\mathrm{cao}=548678}$. Acesso em: 25 nov. 2021.

BRASIL, Câmara dos Deputados. Projeto de Lei n ${ }^{\circ}$ 12.965, de 23 de abril de 2014. Acrescenta o art. 10-A à Lei n ${ }^{0} 12.965$, de 23 de abril de 2014 (Marco Civil da Internet), a fim de dispor sobre a destinação das contas de aplicações de internet após a morte de seu titular. Disponível em: https://www.camara.leg.br/propostas-legislativas/2139508. Acesso em: 25 nov. 2021.

CARVALHO, Luiz Paulo Viera de. Direito das sucessões. 2. ed. São Paulo: Atlas, 2015.

CASTELLS, Manuel. A sociedade em rede. Tradução: Roneide Venâncio Majer.17. ed. São Paulo: Paz e Terra, 2016.

COSTA FILHO, Marco Aurélio de Faria. Patrimônio Digital: Reconhecimento e Herança. Recife: Ed. Nossa Livraria, 2016.

DINIZ, Maria Helena. Curso de direito civil brasileiro: direito das sucessões. 35. ed. São Paulo: Saraiva Jur, 2021.

EIXO DIGITAL. tipos de redes sociais: Os mais utilizados no brasil e no mundo. Disponível em: https://eixo.digital/redes-sociais-mais-utilizados-no-brasil-e-no-mundo/. Acesso em: 25 nov. 2021.

FACEBOOK, Sobre as contas de memorial. Disponível em: https:/ /pt-br.facebook.com/ help/1017717331640041/. Acesso em: 22 jul. 2021

FARIAS, Cristiano Chaves de; ROSENVALD, Nelson. Curso de direito civil: sucessões. 3. ed. Salvador: JusPodivm, 2017.

FIND A GRAVE. A maior coleção de túmulos do mundo. Disponível em: https://pt.findagrave.com/. Acesso em: 09 jul. 2021.

FIUZA, César, Direito Civil Curso Completo. 22. ed. Belo Horizonte: D’Plácido, 2021.

GAGLIANO, Pablo Stolze; PAMPLONA, Filho, Rodolfo. Manual de direito civil: Volume único. São Paulo: Saraiva, 2017.

GONÇALVES, Carlos Roberto. Direito civil brasileiro: Direito das sucessões. v. 7, 11. ed. São Paulo: Saraiva, 2017.

GONÇALVES, Maria Eduarda. Direito da informação: novos direitos e formas de regulação na sociedade da informação. Coimbra: Livraria Almedina, 2003. 
GOOGLE, Gerenciador de contas inativas. Disponível em: https://myaccount.google. com/inactive. Acesso em: 23 jul. 2021;

GRAIEB, Carlos. Vida digital: Quando não há mais segredos. Veja. São Paulo, edição 2125, ano 42, no 32, p. 81, 12 ago. 2009.

INSTAGRAM, Como denunciar a conta de uma pessoa falecida no Instagram? Disponível em: https:/ / help.instagram.com/264154560391256. Acesso em: 09 jul. 2021.

LACERDA, Bruno Torquato Zampier. Bens digitais. Indaiatuba, SP: Foco Jurídico, 2017.

LARA, Moisés Fagundes. Herança Digital. 1. ed. Porto Alegre: Edição Própria, 2016.

LEITE, Eduardo de Oliveira. Comentários ao novo Código Civil. Coordenação de Sálvio de Figueiredo Teixeira. 3. ed. Rio de Janeiro: Forense, 2003.

LENZA, Pedro. Teoria geral da ação civil pública. São Paulo: Revista dos Tribunais, 2005.

LEONARDI, Marcel. Tutela e privacidade na Internet. São Paulo: Saraiva, 2012.

LIMA, Isabela Rocha. Herança Digital: direito sucessório de bens armazenados virtualmente. Brasília, 2013. Disponível em: http:/ / bdm.unb.br/bitstream/10483/6799/1/2013_ IsabelaRochaLima.pdf. Acesso em: 22 jul. 2021.

LÔBO, Paulo. Direito Civil: Sucessões. 3 ed. São Paulo, Saraiva, 2016.

MARMELSTEIN, George. Curso de Direitos Fundamentais. São Paulo: Atlas, 2008.

MAXIMILIANO, Carlos. Direito das sucessões. 2. ed. Rio de Janeiro: Freitas Bastos, 1942.

MEDINA, José Miguel Garcia. Herança Digital e os bens guardados na nuvem. Disponível em https://professormedina.com/2011/11/03/heranca-digital-e-os-bens-guardados-na-nuvem/. Acesso em 23 jul. 2021.

MEIRELES, Rose Melo Vencelau. Autonomia privada e dignidade humana. Rio de Janeiro: Renovar, 2009.

MENDES, Gilmar Ferreira. Direitos fundamentais e controle de constitucionalidade: estudos de direito constitucional. 4 ed. rev. e ampl. São Paulo: Saraiva, 2012.

NEVARES, Ana Luiza Maia. A função promocional do testamento: tendências do direito sucessório. Rio de Janeiro: Renovar, 2009.

NOVELINO, Marcelo. Manual de direito constitucional: Volume único. 9 ed. rev. e atual. Rio de Janeiro: Forense; São Paulo: Método, 2014.

OLIVEIRA, Jaime Gustavo Gonçalves de. Luto digital: plataformas para a gestão da herança digital. 2015.Tese (Doutorado em Engenharia e Gestão de Sistemas de Informação) - Universidade do Minho, Escola de Engenharia Campus de Azurém, Portugal, 2015.

PERLINGIERI, Pietro. Perfis do direito civil: introdução ao direito civil constitucional. 3. ed. São Paulo: Renovar, 2007. 
PINHEIRO, Patrícia Peck. Direito digital. 6. ed. São Paulo: Saraiva, 2016.

PINTO, Maria do Céu Pitanga. A dimensão constitucional do direito de herança: aspectos processuais do inventário e partilha. 2006. Curso de Direito, Faculdade de Vitória - ES. Disponível em: http://www.dominiopublico.gov.br/download/teste/arqs/cp075377. pdf. Acesso em 03 jul. 2021.

PRINZLER, Yuri. Herança digital: novo marco no direito das sucessões. Denis de Souza Luiz. 2015. 74 p. Trabalho de Conclusão de Curso (Graduação em Direito) - Universidade do Sul de Santa Catarina, Florianópolis. Disponível em: https://www.academia.edu/19019650/ Heran\%C3\%A7a_Digital_Novo_Marco_no_Direito_das_Sucess\%C3\%B5es. Acesso em: 23 mar. 2021.

RAMOS, André de Carvalho. Curso de direitos humanos. 4 ed. São Paulo: Saraiva, 2017.

RICARTE, Flávio; MANZEPPI, Eduardo. Ainda sem legislação específica, herança digital requer atenção. Disponível em: https://www.conjur.com.br/2020-fev-17/opiniao-legislacao-especifica-heranca-digital-requer-atencao. Acesso em 23 mar. 2021.

RODRIGUES, Silvio. Direito civil: direito das coisas. 4. reimpr. São Paulo: Saraiva, 2007.

ROHRMANN, Carlos Alberto. Curso de Direito Virtual. Belo Horizonte: Del Rey, 2005.

SANZI, Julia. Herança digital e direito sucessório. Disponível em: https://www.anoreg.org.br/site/2018/08/20/artigo-heranca-digital-e-direito-sucessorio-por-julia-sanzi/. Acesso em: 19 mar. 2021.

SCHREIBER, Anderson. Direitos da personalidade. 3. ed. São Paulo: Atlas, 2014.

SILVA, Jessica Ferreira da. Herança digital: a importância desta temática para os alunos dos cursos da Faculdade de Informação e Comunicação da Universidade Federal de Goiás. Laura Vilela Rodrigues Rezende 2014. Trabalho de Conclusão de Curso - Universidade Federal de Goiás, Goiânia. Disponível em: https://repositorio.bc.ufg.br/bitstream/ ri/10808/1/TCC\%20-\%20Biblioteconomia \%20-\%20J\%c3\%a9ssica \%20Ferreira \%20da \% 20 Silva. Acesso em: 02 jul. 2021.

TARTUCE, Flávio. Direito Civil: direito das sucessões. v. 06, 10. ed. Rio de Janeiro: Forense, 2017.

TEIXEIRA, Daniele Chaves. Arquitetura do planejamento sucessório. 2. ed. Belo Horizonte: Fórum, 2019.

TEPEDINO, Gustavo. Temas de direito civil. 3. ed. Rio de Janeiro: Renovar, 2004.

TWITTER, Como entrar em contato com o Twitter para falar sobre a conta de um familiar falecido. Disponível em: https://help.twitter.com/pt/managing-your-account/contact-twitter-about-a-deceased-family-members-account. Acesso em: 02 jul. 2021.

VELOSO, Zeno. Comentários ao Código Civil. Coordenação de Antônio Junqueira de Azevedo. São Paulo: Saraiva, 2003.

VIRGÍNIO, Maria Adriana Dantas. A Sucessão do Acervo Digital. Disponível em: http:/ / idireitofbv.wikidot.com/sucessaodeacervodigital. Acesso em: 22 jun. 2021. 